\title{
Unusual effect of myo-inositol on phospholipid biosynthesis in Cryptococcus neoformans
}

\author{
Vicki L. Vincent and Lisa S. Klig \\ Author for correspondence: Lisa S. Klig. Tel: +1 310985 2424. Fax: +1 3109852315. \\ e-mail: lsklig@beach1.csulb.edu
}

Department of Biological Sciences, California State University Long Beach, Long Beach, CA 90840, USA

\begin{abstract}
Cryptococcus neoformans is an opportunistic fungal pathogen which preferentially localizes to the inositol-rich environment of the central nervous system. One of its distinguishing traits is its capacity to catabolize inositol. Inositol is a precursor for the synthesis of phosphatidylinositol (PI). This study demonstrated that $C$. neoformans synthesizes inositol. Three inositolcontaining sphingolipids were identified in C. neoformans : ceramide(P-inositol) ${ }_{2}$ mannose, ceramide-P-inositol-mannose, and ceramide-P-inositol. These inositol-containing sphingolipids are typical of fungi but not higher eukaryotes. The effect of inositol on the membrane lipid composition of C. neoformans was also examined. In contrast to the nonpathogenic yeast Saccharomyces cerevisiae, neither the PI composition nor the synthesis of methylated phospholipids was altered by exogenous inositol. Hence, C. neoformans appears to have a metabolic mechanism for maintaining a steady lipid composition regardless of the inositol in its environment.
\end{abstract}

Keywords: Cryptococcus neoformans, inositol, phospholipids

\section{INTRODUCTION}

Cryptococcus neoformans is an opportunistic fungal pathogen that infects humans. It is present but harmless in the respiratory tract of many healthy individuals (Randhawa \& Paliwal, 1979). Infections in immunocompromised individuals usually manifest as meningoencephalitis (Kwon-Chung \& Bennett, 1992). Localization of this organism to the inositol-rich environment of the central nervous system (CNS) (Spector \& Lorenzo, 1975) differs from systemic infections with the fungal pathogens Candida albicans (Odds, 1987) and Aspergillus spp. (Musial et al., 1988).

Studies of $C$. neoformans have bcen stimulated by increasing numbers of cryptococcal infections (KwonChung \& Edman, 1992) and a lack of effective antifungal therapies (Clark et al., 1990). Four biological characteristics have been implicated in the pathogenicity of $C$. neoformans: (1) polysaccharide capsule (Bulmer et al., 1967; Dykstra et al., 1977; Fromtling et al., 1982;

\footnotetext{
Abbreviations: CNS, central nervous system; DAG, diacylglycerol; IPC, ceramide-P-inositol; MIPC, ceramide-P-inositol-mannose; $\mathbf{M}(\mathbf{I P})_{2} \mathrm{C}_{\text {, }}$ ceramide-(P-inositol), mannose; $\mathrm{N}$-MTF, $\mathrm{N}$-methyltransferase; $\mathrm{PC}$, phosphatidylcholine; PDME, phosphatidyldimethylethanolamine; $P E$, phosphatidylethanolamine; PI, phosphatidylinositol; PMME, phosphatidylmonomethylethanolamine; PS, phosphatidylserine; SAM, Sadenosylmethionine.
}

Jacobson et al., 1982; Kozel \& Cazin, 1971; Kozel \& Mastroianni, 1976; Kozel, 1977; Kwon-Chung \& Rhodes, 1986); (2) phenoloxidase activity (Jacobson \& Emery, 1991; Kwon-Chung et al., 1982; Kwon-Chung \& Rhodes, 1986; Polacheck et al., 1982, 1990; Rhodes et al., 1982; Wang \& Casadevall, 1994); (3) ability to grow at $37^{\circ} \mathrm{C}$ (Kwon-Chung \& Rhodes, 1986; Rhodes et al., 1982 ); and (4) $\alpha$ mating type (Kwon-Chung \& Bennett, 1978; Kwon-Chung et al., 1992; Moore \& Edman, 1993). Further identification of unique biochemical and genetic characteristics of this organism may aid in the development of new antifungal treatments.

C. neoformans has the distinctive ability to use inositol as a sole carbon source (Barnett, 1976). This trait has been used clinically for a number of years to identify cryptococcal infections (Konemane \& Roberts, 1985). Inositol is a six-carbon sugar and a precursor for the synthesis of phosphatidylinositol (PI), a major membrane phospholipid (Hokin \& Hokin, 1953; Paulus \& Kennedy, 1960). PI is an essential structural component of membranes (Hill et al., 1990) and is also an anchor for certain membrane proteins (Cross, 1990). Moreover, PI and its phosphorylated metabolites are integral parts of the signal transduction pathway essential for balanced cellular growth (Berridge \& Irvine, 1984). PI is also the precursor for the synthesis of ceramide-(P-inositol $)_{2}$ mannose $\left[\mathrm{M}(\mathrm{IP})_{2} \mathrm{C}\right]$, ceramide-P-inositol-mannose (MIPC) and ceramide-P-inositol (IPC), three inositol-containing 


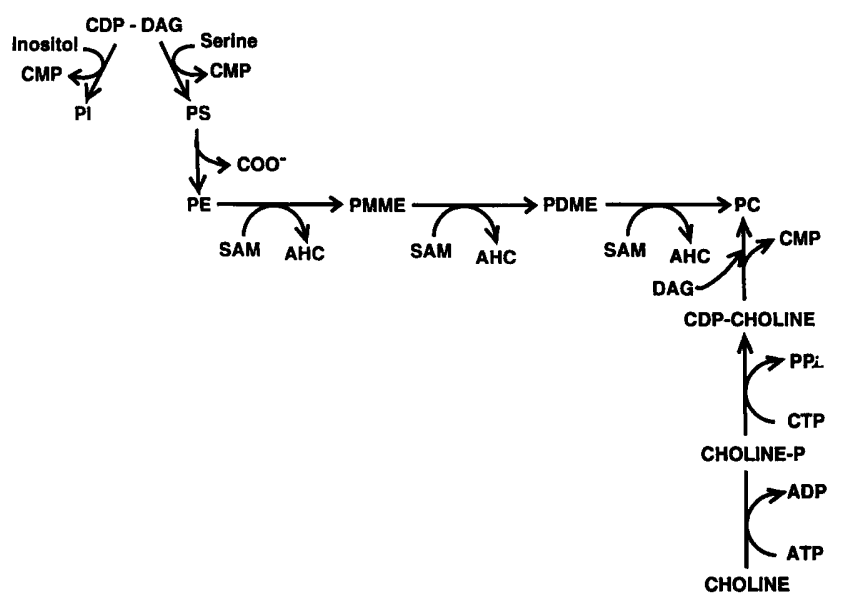

Fig. 1. Phospholipid biosynthetic pathway. AHC, adenosylhomocysteine.

sphingolipids identified and characterized in Saccharomyces cerevisiae (Smith \& Lester, 1974; Steiner \& Lester, 1972; Steiner et al., 1969).

Inositol-containing sphingolipids have not been observed in higher eukaryotes, however, other sphingolipids and their degradation products have been shown to affect cellular differentiation and proliferation in mammalian cells (Olivera et al., 1992). In yeast, inability to synthesize sphingolipids results in increased cell density, loss of ability to divide and ultimately loss of viability (Buede et al., 1991; Dickson et al., 1990; Pinto et al., 1992).

The phospholipid biosynthetic pathway (Fig. 1) and its regulation have been studied in the nonpathogenic yeast $S$. cerevisiae and in the pathogenic yeast $C$. albicans (Carman \& Henry, 1989). The presence of exogenous inositol in the growth medium of $S$. cerevisiae and $C$. albicans shifts phospholipid biosynthesis toward the formation of PI at the expense of methylated phospholipid synthesis (Bailis et al., 1987; Kelley et al., 1988; Klig et al., 1985; Poole et al., 1986). Both $S$. cerevisiae and $C$. albicans are capable of phosphatidylcholine (PC) synthesis by two pathways: de novo PC synthesis via methylation of phosphatidylethanolamine (PE) (Klig et al., 1990; Steiner \& Lester, 1972) or reaction of CDP-activated choline with diacylglycerol (DAG) (Kennedy \& Weiss, 1956; Klig et al., 1990). In C. albicans, the addition of exogenous choline decreases the synthesis of PC by reducing the activity of the $N$-methyltransferases (N-MTFs) (Klig et al., 1990). In $S$. cerevisiae, N-MTF activity decreases in response to choline only if inositol is present (Klig et al., 1988; Waechter \& Lester, 1973; Yamashita et al., 1982).

Prior research has established the overall lipid composition of $C$. neoformans at various growth phases in complex media (Itoh et al., 1975; Itoh \& Kaneko, 1977). This study examined the effects of exogenous inositol on growth, lipid synthesis and lipid composition of C. neoformans. Inositol biosynthesis by $C$. neoformans is demonstrated. Furthermore, $C$. neoformans membrane phospholipid composition is shown to be unaltered by the availability of inositol. These data suggest that C. neoformans utilizes a novel regulatory mechanism for inositol metabolism in a programme of balanced cell growth.

\section{METHODS}

Strains and media. All experiments were performed with two serotype D strains of Cryptococcus neoformans, C20a and C21 $\alpha$, obtained from Dr J. Edman at the University of California, San Francisco, USA. Saccharomyces cerevisiae strain A6 (ade6 a) was used as a control.

All strains were maintained on YEPD ( $1 \%$, w/v, yeast extract, $2 \%$, w/v, Difco bacto-peptone, $2 \%$, w $/ v$, glucose, $2 \%, w / v$, agar) plates. For experimental procedures, strains were grown in complete synthetic defined (SD) medium (lacking inositol) as described previously (Klig et al., 1990). SD medium was supplemented with $75 \mu \mathrm{M}$ inositol as indicated. In SD-inositol medium, $110 \mathrm{mM}$ inositol was substituted for glucose as the carbon source. Where indicated in the text, the media were supplemented with $10 \mathrm{mM}$ choline.

Determination of growth parameters. The growth rate of each yeast strain was determined in SD medium with and without inositol and/or choline supplementation, and in SDinositol medium with and without choline supplementation. Cultures $(10 \mathrm{ml})$ were inoculated and grown overnight at $30^{\circ} \mathrm{C}$ with shaking. Cultures were diluted with fresh medium to an $\mathrm{OD}_{600}$ of $0 \cdot 1\left(\sim 10^{6}\right.$ cells $\left.\mathrm{ml}^{-1}\right)$. The cells were then incubated, shaking, at $30^{\circ} \mathrm{C}$ and aliquots were removed at the times indicated. Cell numbers were determined spectrophotometrically $\left(\mathrm{OD}_{600}\right)$ and by viability plating.

Pulse labelling to examine lipid synthesis. Strains C20a, C21 $\alpha$ and $\mathrm{A} 6$ were grown at $30^{\circ} \mathrm{C}$ to mid-exponential phase. The

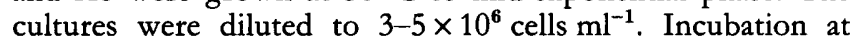
$30^{\circ} \mathrm{C}$ was continued until growth resumed and the cells underwent at least one doubling. The cells were then pulse labelled for $15 \mathrm{~min}$ with $0.1 \mathrm{mCi}^{32} \mathrm{P} \mathrm{ml}^{-1}\left(3.7 \mathrm{MBq}^{32} \mathrm{P} \mathrm{ml}^{-1}\right)$ (8500-9120 mCi mmol ${ }^{-1}$; NEN/Dupont) or for $30 \mathrm{~min}$ with $0.5 \mu \mathrm{Ci}\left[\right.$ metbyl $\left.L^{14} \mathrm{C}\right]$ methionine $\mathrm{ml}^{-1} \quad\left(18.5 \mathrm{kBq}\left[\right.\right.$ metby $\left.L^{14} \mathrm{C}\right]-$ methionine $\left.\mathrm{ml}^{-1}\right)\left(43.4 \mathrm{mCi} \mathrm{mmol}^{-1}\right.$; NEN/Dupont) or $1.0 \mu \mathrm{Ci}$ $\left[{ }^{14} \mathrm{C}\right]$ choline $\mathrm{ml}^{-1}\left(37 \mathrm{kBq}\left[{ }^{14} \mathrm{C}\right]\right.$ choline $\left.\mathrm{ml}^{-1}\right)\left(55 \mathrm{mCi} \mathrm{mmol}^{-1}\right.$; ICN).

Steady state in vivo labelling to examine lipid composition. Strains $\mathrm{C} 20 \mathrm{a}, \mathrm{C} 21 \alpha$ and $\mathrm{A} 6$ were grown in the media indicated at $30^{\circ} \mathrm{C}$. The cultures were diluted with fresh media and grown for five to six generations, to mid-exponential phase, in the presence of $0.01 \mathrm{mCi}^{32} \mathrm{P} \mathrm{ml}^{-1}\left(0.37 \mathrm{MBq}^{32} \mathrm{P} \mathrm{ml}^{-1}\right)$ (8500-9120 $\mathrm{mCi} \mathrm{mmol}^{-1}$; NEN/Dupont).

Phospholipid and sphingolipid extraction and separation. The yeast cells were broken and the lipids extracted essentially as described by Atkinson (1984). The samples were dried under a stream of nitrogen gas, resuspended in $40 \mu \mathrm{l}$ chloroform/ methanol $(2: 1, \mathrm{v} / \mathrm{v})$, and spotted on Whatman SG81 silicaimpregnanted paper (dipped in $2 \%, \mathrm{w} / \mathrm{v}, \mathrm{EDTA}, \mathrm{pH} 7 \cdot 1$ ). The lipids were separated by two-dimensional chromatography. Solvent I for phospholipid separation contained: $198 \mathrm{ml}$ chloroform, $81 \mathrm{ml}$ methanol, $12.5 \mathrm{ml} 28.8 \%$ (w/v) ammonium hydroxide and $0.6 \mathrm{ml} 5 \%(\mathrm{w} / \mathrm{v})$ butylated hydroxytoluene in chloroform. Solvent II contained: $192 \mathrm{ml}$ chloroform, $24 \mathrm{ml}$ methanol, $6 \mathrm{ml}$ water, $30 \mathrm{ml}$ glacial acetic acid, and $0.6 \mathrm{ml}$ $5 \%(\mathrm{w} / \mathrm{v})$ butylated hydroxytoluene in chloroform. For sphingolipid separation, solvent I contained: $135 \mathrm{ml}$ chloro- 
form, $105 \mathrm{ml}$ methanol, $15 \mathrm{ml}$ water, $10 \mathrm{ml} 28.8 \%$ (w/v) ammonium hydroxide, and $0.6 \mathrm{ml} 5 \%(\mathrm{w} / \mathrm{v})$ butylated hydroxytoluene in chloroform. Solvent II contained: $150 \mathrm{ml}$ chloroform, $61 \mathrm{ml}$ methanol, $40 \mathrm{ml}$ glacial acetic acid, $16 \mathrm{ml}$ water, and $0.54 \mathrm{ml} 5 \%(\mathrm{w} / \mathrm{v})$ butylated hydroxytoluene in chloroform. ${ }^{14} \mathrm{C}$-labelled methylated lipids were separated by one-dimensional chromatography. The solvent consisted of chloroform/methanol $/ 28.8 \%(\mathrm{w} / \mathrm{v})$ ammonium hydroxide (66:17:3, by vol.).

Autoradiographs, obtained by exposing the chromatograms to Kodak AR-5 X-ray film, were used to locate the labelled lipids. Lipids were identified by their migration patterns relative to standards. The samples were cut from the chromatograms and counted by liquid scintillation.

Inositol excretion assay. C20a or $\mathrm{C} 21 \alpha$ was grown on SDinositol medium for up to 1 week. Cells were then transferred to complete SD plates (lacking inositol), sprayed with $S$. cerevisiae indicator strain AID (ade-1/ade-1, inol-13/inol-13, lys-2/+, $+/$ ade $5, a / \alpha)$ (Greenberg et al., 1982) and incubated at $30^{\circ} \mathrm{C}$. Growth of the indicator strain, which produces red colonies in the presence of inositol, was evaluated.

Analysis of data. c.p.m. incorporated into each lipid was determined. The percentage of each lipid relative to the total amount of label incorporated in all lipids was then calculated. The mean \pm one standard error of the mean for all experimental trials was determined. One-way or two-way analysis of variance was used to determine the significance of the effects of the precursors on phospholipid synthesis or composition.

\section{RESULTS}

\section{Growth parameters of $C$. neoformans}

Two C. neoformans strains, $\mathrm{C} 20 \mathrm{a}$ and $\mathrm{C} 21 \alpha$, and S. cerevisiae strain $\mathrm{A} 6$, were grown at $30^{\circ} \mathrm{C}$ in $\mathrm{SD}$ medium with or without inositol supplementation and in SD-inositol medium without glucose. The doubling times for $C$. neoformans strains C20a and C21 $\alpha$ in SD medium with or without inositol supplementation $(75 \mu \mathrm{M})$ were approximately $3 \mathrm{~h}$ (Table 1 ). Both strains entered stationary phase at approximately $3 \times 10^{7}$ cells $\mathrm{ml}^{-1}$ in SD

Table 1. Growth parameters of $C$. neoformans and S. cerevisiae

The doubling times in mid-exponential phase are shown.

\begin{tabular}{|c|c|c|c|c|}
\hline \multirow{2}{*}{$\begin{array}{l}\text { Yeast } \\
\text { strain }\end{array}$} & \multirow{2}{*}{$\begin{array}{l}\text { Glucose } \\
\text { concn }\end{array}$} & \multirow{2}{*}{$\begin{array}{l}\text { Inositol } \\
\text { concn }\end{array}$} & \multicolumn{2}{|c|}{ Growth rate (h) } \\
\hline & & & $\begin{array}{l}\text { Without } \\
\text { choline }\end{array}$ & $\begin{array}{c}\text { With } \\
\text { choline } \\
(10 \mathrm{mM})\end{array}$ \\
\hline \multirow[t]{2}{*}{ A6 } & $110 \mathrm{mM}$ & 0 & 3 & 3 \\
\hline & $110 \mathrm{mM}$ & $75 \mu \mathrm{M}$ & 3 & 3 \\
\hline \multirow[t]{3}{*}{$\mathrm{C} 20 \mathrm{a}$} & $110 \mathrm{mM}$ & 0 & 3 & 3 \\
\hline & $110 \mathrm{mM}$ & $75 \mu \mathrm{M}$ & 3 & 3 \\
\hline & 0 & $110 \mathrm{mM}$ & 8 & 12 \\
\hline \multirow[t]{3}{*}{$\mathrm{C} 21 \alpha$} & $110 \mathrm{mM}$ & 0 & 3 & 3 \\
\hline & $110 \mathrm{mM}$ & $75 \mu \mathrm{M}$ & 3 & 3 \\
\hline & 0 & $110 \mathrm{mM}$ & 8 & 12 \\
\hline
\end{tabular}

medium regardless of inositol supplementation. The growth rates were not altered by the addition of choline to the growth media. In SD-inositol medium (no glucose) the doubling times of both strains of $C$. neoformans were approximately $8 \mathrm{~h}$, and there were approximately

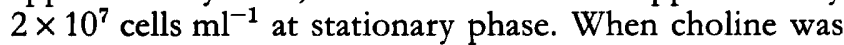
added to SD-inositol medium, the growth rate of both $C$. neoformans strains was drastically decreased, to a doubling time of approximately $12 \mathrm{~h}$. Similar to $C$. neoformans, $S$. cerevisiae strain A6 doubled approximately once every $3 \mathrm{~h}$ in SD medium with or without inositol supplementation $(75 \mu \mathrm{M})$. However, $S$. cerevisiae did not grow in SDinositol medium without glucose.

\section{Phospholipid synthesis by C. neoformans}

C. neoformans strains $\mathrm{C} 20 \mathrm{a}$ and $\mathrm{C} 21 \alpha$ synthesized typically eukaryotic phospholipids. Both strains synthesized the four major phospholipids PI, PS, PC and PE (Table 2). Trace amounts of the methylated phospholipids PMME and PDME were also synthesized. Pulse labelling with ${ }^{32} \mathrm{P}$ for 15 min demonstrated the synthesis of PI by strains $\mathrm{C} 20 \mathrm{a}$ and $\mathrm{C} 21 \alpha$ regardless of the inositol concentration in the growth medium (Table 2). In $C$. neoformans strain C20a, PI accounted for approximately $30 \%$ of the total phospholipids synthesized during a period of $15 \mathrm{~min}$. There was not a statistically significant difference in the phospholipids synthesized in strain C20a regardless of whether inositol was absent from the growth medium, present in micromolar amounts, or provided in millimolar amounts as the sole energy source (PI, $P=0.077$; PS, $P=0.411$; PC, $P=0.257$; PE, $P=0.472$ ). In strain $\mathrm{C} 21 \alpha$, inositol provided as the sole carbon source to media lacking glucose had a slight but statistically significant effect on the synthesis of PI $(P=0.013)$ and PS $(P=$ 0.012 ). In contrast, in $S$. cerevisiae micromolar amounts of inositol added to media with glucose as a carbon source had a drastic effect on the synthesis of PI $(P<0.0001)$, PC $(P=0.001)$ and PE $(P=0.003)$. PI represented $27.6 \%$ of the phospholipids synthesized in $15 \mathrm{~min}$ by $S$. cerevisiae grown in medium without inositol supplementation, whereas in growth medium containing $75 \mu \mathrm{M}$ inositol PI accounted for $51.6 \%$ of the phospholipids synthesized.

\section{Phospholipid composition of C. neoformans}

To examine the effect of inositol on the phospholipid composition of $C$. neoformans, cultures were steady-state labelled with ${ }^{32} \mathrm{P}$ for five to six generations (Fig. 2). The PI percentage of total membrane phospholipids was not altered by exogenous inositol in either strain $\mathrm{C} 20 \mathrm{a}$ or $\mathrm{C} 21 \alpha$ (Table 3). Even when inositol was provided as the sole cabon source, PI remained approximately $8 \%$ of the total phospholipids labelled. The percentage of PI in the membranes of $C$. neoformans was similar to that of $S$. cerevisiae grown without inositol. In $C$. neoformans, the methylated phospholipid pathway which results in the synthesis of PC was also relatively unaltered by exogenous inositol, although some fluctuation is noted in strain C21 $\alpha$ $(P=0.017)$. In contrast, inositol caused a significant increase in the proportion of PI $(P<0.0001)$, and a 
Table 2. Analysis of phospholipid synthesis in C. neoformans by pulse labelling

Cells were labelled for $15 \mathrm{~min}$ with ${ }^{32} \mathrm{P}_{1}$ in defined media supplemented as indicated. Results show the mean \pm one standard error of the mean for at least three experiments.

\begin{tabular}{|c|c|c|c|c|c|c|c|}
\hline \multirow{2}{*}{$\begin{array}{l}\text { Yeast } \\
\text { strain }\end{array}$} & \multirow{2}{*}{$\begin{array}{c}\text { Glucose } \\
\text { concn }\end{array}$} & \multirow{2}{*}{$\begin{array}{l}\text { Inositol } \\
\text { concn }\end{array}$} & \multicolumn{5}{|c|}{ Phospholipid (\%) } \\
\hline & & & PI & PS & PC & PE & Other* \\
\hline \multirow[t]{2}{*}{ A6 } & $110 \mathrm{mM}$ & 0 & $27 \cdot 6 \pm 2 \cdot 1$ & $30 \cdot 4 \pm 5 \cdot 6$ & $4 \cdot 4 \pm 0 \cdot 8$ & $8 \cdot 1 \pm 0 \cdot 9$ & $20 \cdot 9 \pm 5 \cdot 4$ \\
\hline & $110 \mathrm{mM}$ & $75 \mu \mathrm{M}$ & $51 \cdot 6 \pm 1 \cdot 2$ & $28 \cdot 3 \pm 1 \cdot 1$ & $1 \cdot 2 \pm 0.3$ & $12 \cdot 0 \pm 0.5$ & $6.8 \pm 0.6$ \\
\hline \multirow[t]{3}{*}{$\mathrm{C} 20 \mathrm{a}$} & $110 \mathrm{mM}$ & 0 & $28 \cdot 7 \pm 0 \cdot 9$ & $38 \cdot 3 \pm 2 \cdot 6$ & $13 \cdot 0 \pm 2 \cdot 0$ & $7 \cdot 3 \pm 0 \cdot 7$ & $11 \cdot 9 \pm 2 \cdot 2$ \\
\hline & $110 \mathrm{mM}$ & $75 \mu \mathrm{M}$ & $27 \cdot 8 \pm 1 \cdot 2$ & $34 \cdot 9 \pm 3 \cdot 1$ & $15 \cdot 3 \pm 2 \cdot 8$ & $7 \cdot 0 \pm 0.7$ & $11 \cdot 8 \pm 2 \cdot 5$ \\
\hline & 0 & $110 \mathrm{mM}$ & $32 \cdot 2 \pm 1 \cdot 7$ & $32 \cdot 0 \pm 4 \cdot 1$ & $9.5 \pm 1.6$ & $9 \cdot 0 \pm 2 \cdot 0$ & $17 \cdot 4 \pm 3.6$ \\
\hline \multirow[t]{3}{*}{$\mathrm{C} 21 \alpha$} & $110 \mathrm{mM}$ & 0 & $26.4 \pm 1.4$ & $41 \cdot 4 \pm 1.5$ & $12 \cdot 1 \pm 2 \cdot 2$ & $8.6 \pm 0.8$ & $11 \cdot 2 \pm 1 \cdot 2$ \\
\hline & $110 \mathrm{mM}$ & $75 \mu \mathrm{M}$ & $28 \cdot 5 \pm 1 \cdot 5$ & $40 \cdot 1 \pm 1 \cdot 5$ & $12 \cdot 6 \pm 1.5$ & $8.7 \pm 0.3$ & $9 \cdot 2 \pm 1 \cdot 5$ \\
\hline & 0 & $110 \mathrm{mM}$ & $36 \cdot 9 \pm 2 \cdot 9$ & $31 \cdot 0 \pm 3 \cdot 3$ & $11 \cdot 4 \pm 2 \cdot 6$ & $7 \cdot 9 \pm 0 \cdot 2$ & $15 \cdot 6 \pm 1.9$ \\
\hline
\end{tabular}

* Includes the pooled percentages of the minor phospholipids, cardiolipin, phosphatidylglycerol, CDP-DAG, phosphatic acid, PMME, PDME and other unidentified lipids present in trace amounts.

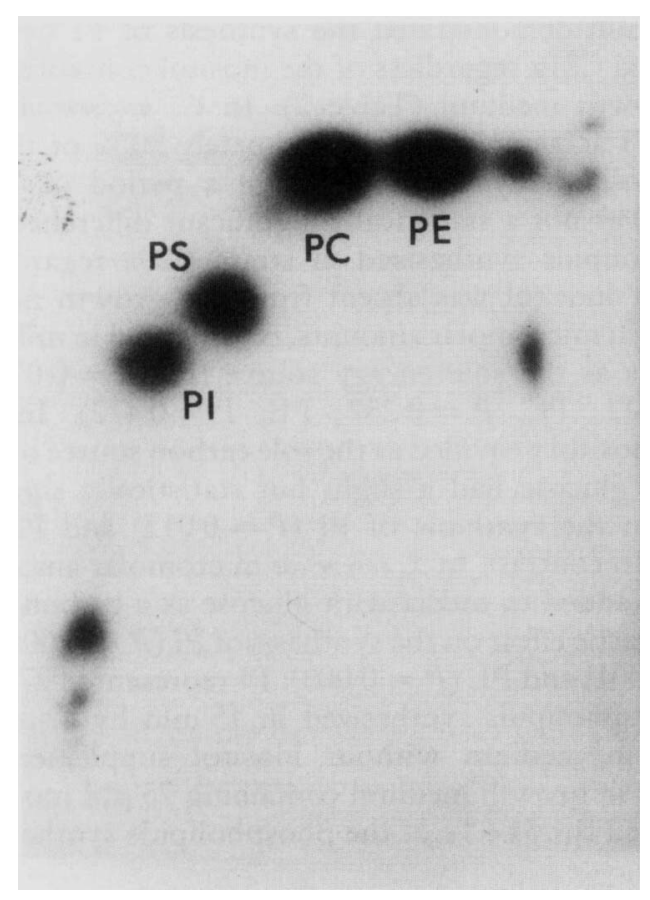

Fig. 2. Phospholipid composition. Autoradiogram of a twodimensional chromatographic separation of ${ }^{32 p}$ steady-state labelled phospholipids from strain C20a grown in SD-glucose medium.

decrease in the proportion of PC $(P=0.005)$ in S. cerevisiae strain A6.

\section{PC synthesis by $\mathrm{C}$. neoformans}

C. neoformans cells were pulse labelled with $\left[{ }^{14} \mathrm{C}\right]$ choline to establish the existence of an auxiliary pathway for the synthesis of PC. This pathway was originally described in S. cerevisiae (Kennedy \& Weiss, 1956). After a $30 \mathrm{~min}$ pulse with $\left[{ }^{14} \mathrm{C}\right]$ choline, 49000 and 65000 c.p.m. were incorporated into PC by 1.45 and $2.45 \times 10^{7}$ cells of strains $\mathrm{C} 20 \mathrm{a}$ and $\mathrm{C} 21 \alpha$, respectively. The total ${ }^{14} \mathrm{C}$ incorporation into PC was not altered by the presence of inositol.

\section{Methylated phospholipid synthesis by $C$. neoformans}

To examine the effects of inositol and choline on N-MTF activity in C. neoformans, pulse labelling experiments with $\left[\right.$ methyl $\left.{ }^{14} \mathrm{C}\right]$ methionine were performed (Fig. 3). [metbyl$\left.{ }^{14} \mathrm{C}\right]$ Methionine can be taken up by cells and converted to $\left[{ }^{14} \mathrm{C}\right]$-adenosylmethionine (SAM). The $\left[{ }^{14} \mathrm{C}\right] \mathrm{SAM}$ can provide the methyl group for the synthesis of PMME, PDME and PC. The relative proportions of ${ }^{14} \mathrm{C}$-labelled PMME, PDME and PC synthesized by C20a and C21 $\alpha$ were not significantly altered by the presence or absence of inositol in the growth medium (Table 4). Addition of choline to the growth media, however, resulted in a statistically significant decrease in the proportion of PC (C20a, $P<0.0001 ; \mathrm{C} 21 \alpha, P=0.018)$ and an increase in the proportion of PMME (C20a, $P<0.0001$; C21 $\alpha$, $P<0.024)$. Inositol did not have a significant effect on methylated lipid synthesis in C. neoformans. In S. cerevisiae, choline significantly decreased PC $(P<0.0001)$ and increased PMME $(P<0.0001)$ synthesis. The addition of both inositol and choline to the growth medium of $S$. cerevisiae further decreased the proportion of PC $(P=0.003)$ and increased the proportion of PMME $(P<0.0001)$ and PDME $(P<0.0001)$.

Direct comparison of the total c.p.m. incorporated by the $N$-MTFs into the methylated phospholipids clearly revealed the effects of choline and inositol (Table 5). $\mathrm{N}$ MTF activity of strain C20a was repressed more than threefold in the presence of choline. Similarly the N-MTF activity in C21 $\alpha$ was repressed more than sixfold by choline. This repression was not dependent on or affected by inositol. In contrast, the repression of total N-MTF activity in $S$. cerevisiae by either exogenous inositol or choline was less than twofold. However, in the presence of both inositol and choline N-MTF activity in S. cerevisiae was repressed 25 -fold. 
Table 3. Analysis of phospholipid composition of C. neoformans by steady-state labelling

Cells were labelled for five to six generations with ${ }^{32} \mathrm{P}_{\mathrm{i}}$ in defined media supplemented as indicated. Results show the mean \pm one standard error of the mean for at least four experiments.

\begin{tabular}{|cccccccc}
\hline \multirow{2}{*}{$\begin{array}{c}\text { Yeast } \\
\text { strain }\end{array}$} & $\begin{array}{c}\text { Glucose } \\
\text { concn }\end{array}$ & $\begin{array}{c}\text { Inositol } \\
\text { concn }\end{array}$ & \multicolumn{3}{c|}{ Phospholipid (\%) } \\
\cline { 3 - 7 } & & & PI & PS & PC & PE & Other* \\
\hline \multirow{2}{*}{$\mathrm{A} 6$} & $110 \mathrm{mM}$ & 0 & $9 \cdot 2 \pm 0 \cdot 8$ & $10 \cdot 7 \pm 1 \cdot 3$ & $49 \cdot 2 \pm 2 \cdot 7$ & $17 \cdot 8 \pm 2 \cdot 0$ & $20 \cdot 8 \pm 2 \cdot 6$ \\
& $110 \mathrm{mM}$ & $75 \mu \mathrm{M}$ & $28 \cdot 1 \pm 0 \cdot 1$ & $9 \cdot 0 \pm 0 \cdot 9$ & $30 \cdot 4 \pm 1 \cdot 8$ & $23 \cdot 8 \pm 1 \cdot 7$ & $13 \cdot 0 \pm 2 \cdot 2$ \\
$\mathrm{C} 20 \mathrm{a}$ & $110 \mathrm{mM}$ & 0 & $7 \cdot 6 \pm 0 \cdot 2$ & $11 \cdot 8 \pm 0 \cdot 6$ & $42 \cdot 3 \pm 1 \cdot 6$ & $27 \cdot 7 \pm 2 \cdot 3$ & $13 \cdot 4 \pm 2 \cdot 2$ \\
& $110 \mathrm{mM}$ & $75 \mu \mathrm{M}$ & $10 \cdot 0 \pm 1 \cdot 8$ & $11 \cdot 6 \pm 0 \cdot 7$ & $41 \cdot 7 \pm 2 \cdot 3$ & $24 \cdot 2 \pm 0 \cdot 8$ & $11 \cdot 2 \pm 2 \cdot 5$ \\
& 0 & $110 \mathrm{mM}$ & $7 \cdot 9 \pm 0 \cdot 5$ & $11 \cdot 2 \pm 0 \cdot 5$ & $41 \cdot 5 \pm 3 \cdot 0$ & $27 \cdot 0 \pm 2 \cdot 9$ & $12 \cdot 0 \pm 2 \cdot 4$ \\
$\mathrm{C} 21 \alpha$ & $110 \mathrm{mM}$ & 0 & $6 \cdot 9 \pm 0 \cdot 5$ & $8 \cdot 0 \pm 0 \cdot 5$ & $45 \cdot 1 \pm 1 \cdot 7$ & $23 \cdot 8 \pm 2 \cdot 7$ & $15 \cdot 6 \pm 4 \cdot 5$ \\
& $110 \mathrm{mM}$ & $75 \mu \mathrm{M}$ & $8 \cdot 7 \pm 0 \cdot 6$ & $7 \cdot 8 \pm 1 \cdot 2$ & $40 \cdot 1 \pm 2 \cdot 5$ & $28 \cdot 1 \pm 1 \cdot 9$ & $20 \cdot 4 \pm 2 \cdot 9$ \\
& 0 & $110 \mathrm{mM}$ & $8 \cdot 0 \pm 0 \cdot 1$ & $8 \cdot 1 \pm 1 \cdot 6$ & $53 \cdot 1 \pm 3 \cdot 5$ & $21 \cdot 2 \pm 1 \cdot 6$ \\
\hline
\end{tabular}

* Includes the pooled percentages of the minor phospholipids, cardiolipin, phosphatidylglycerol, CDP-DAG, phosphatic acid, PMME, PDME and other unidentified lipids present in trace amounts.

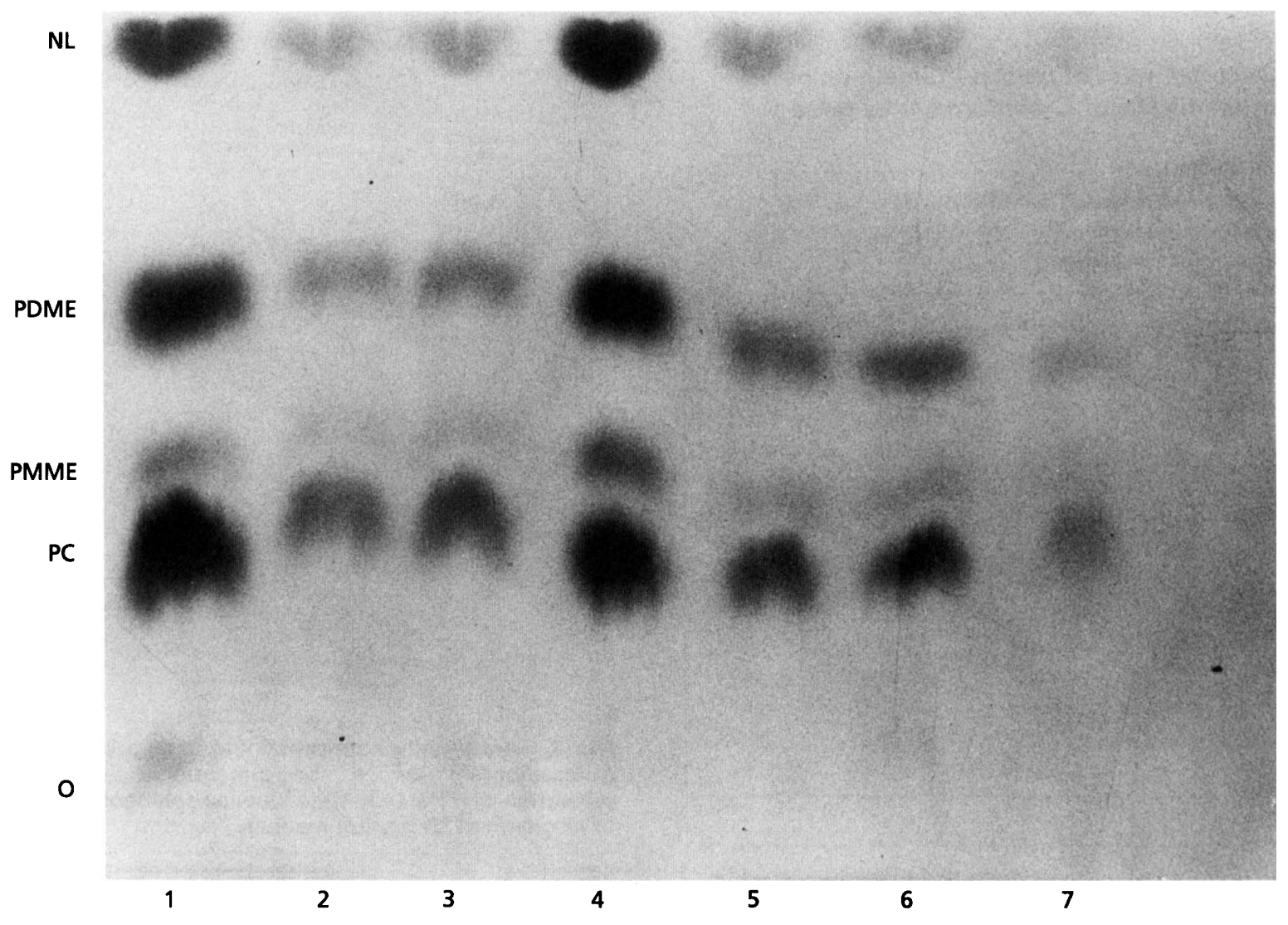

Fig. 3. Methylated phospholipid synthesis. Autoradiogram of a one-dimensional chromatographic separation of [methyl${ }^{14} \mathrm{C}$ ]methionine-labelled methylated phospholipids. Lipids were extracted from yeast grown in SD medium without inositol (lane 1, A6; lane 2, C20a; lane 3, C21 $)$ ), in SD medium with $75 \mu \mathrm{M}$ inositol (lane 4, A6; lane 5, C20a; lane 6, C21 $\alpha$ ) or in SD-inositol medium (lane 7, C20a). Abbreviations: O, origin; NL, neutral lipids.

\section{Inositol-phosphate-containing sphingolipids in \\ C. neoformans}

The presence of inositol-phosphate-containing sphingolipids in $C$. neoformans was established by steady-state labelling of the lipids with ${ }^{32} \mathrm{P} .{ }^{32} \mathrm{P}$-labelled lipids extracted from $C$. neoformans were identified by their migration relative to the standards IPC, MIPC and M(IP) ${ }_{2} \mathrm{C}$ (Fig. 4). These three inositol-containing sphingolipids were found in the membranes of $C$. neoformans regardless of inositol 
Table 4. Analysis of methylated phospholipid synthesis in C. neoformans by pulse labelling

Cells were labelled for $30 \mathrm{~min}$ with $\left[\right.$ metbyl $\left.-^{14} \mathrm{C}\right]$ methionine in defined media supplemented as indicated. Results show the mean \pm one standard error of the mean of at least four experiments. NA, Not available.

\begin{tabular}{|c|c|c|c|c|c|c|c|c|}
\hline \multirow{3}{*}{$\begin{array}{l}\text { Yeast } \\
\text { strain }\end{array}$} & \multirow{3}{*}{$\begin{array}{l}\text { Glucose } \\
\text { concn }\end{array}$} & \multirow{3}{*}{$\begin{array}{l}\text { Inositol } \\
\text { concn }\end{array}$} & \multicolumn{6}{|c|}{ Phospholipid (\%) } \\
\hline & & & \multicolumn{3}{|c|}{ Without choline } & \multicolumn{3}{|c|}{ With choline (10 mM) } \\
\hline & & & PC & PMME & PDME & PC & PMME & PDME \\
\hline \multirow[t]{2}{*}{ A6 } & $110 \mathrm{mM}$ & 0 & $73 \cdot 7 \pm 4 \cdot 0$ & $4 \cdot 7 \pm 1 \cdot 2$ & $20 \cdot 9 \pm 2 \cdot 9$ & $56 \cdot 4 \pm 2 \cdot 2$ & $10 \cdot 1 \pm 1 \cdot 2$ & $32 \cdot 6 \pm 1 \cdot 1$ \\
\hline & $110 \mathrm{mM}$ & $75 \mu \mathrm{M}$ & $73 \cdot 2 \pm 2 \cdot 6$ & $6.4 \pm 1.5$ & $24 \cdot 3 \pm 3 \cdot 4$ & $33.6 \pm 2.2$ & $26 \cdot 7 \pm 1 \cdot 0$ & $38 \cdot 2 \pm 0 \cdot 8$ \\
\hline \multirow[t]{3}{*}{$\mathrm{C} 20 \mathrm{a}$} & $110 \mathrm{mM}$ & 0 & $58 \cdot 4 \pm 1.8$ & $14 \cdot 6 \pm 1 \cdot 1$ & $27 \cdot 0 \pm 0 \cdot 8$ & $49 \cdot 0 \pm 2 \cdot 6$ & $24 \cdot 0 \pm 3 \cdot 8$ & $34 \cdot 5 \pm 3 \cdot 3$ \\
\hline & $110 \mathrm{mM}$ & $75 \mu \mathrm{M}$ & $56 \cdot 0 \pm 1 \cdot 7$ & $14 \cdot 2 \pm 1 \cdot 3$ & $31 \cdot 0 \pm 2 \cdot 7$ & $44 \cdot 1 \pm 1 \cdot 8$ & $22 \cdot 0 \pm 1 \cdot 2$ & $33.9 \pm 1 \cdot 7$ \\
\hline & 0 & $110 \mathrm{mM}$ & $58 \cdot 4 \pm 3.5$ & $15 \cdot 3 \pm 2 \cdot 0$ & $25 \cdot 8 \pm 1 \cdot 8$ & NA & NA & NA \\
\hline \multirow[t]{3}{*}{$\mathrm{C} 21 \alpha$} & $110 \mathrm{mM}$ & 0 & $55 \cdot 0 \pm 2 \cdot 0$ & $15 \cdot 9 \pm 1 \cdot 8$ & $29 \cdot 4 \pm 1.5$ & $45 \cdot 2 \pm 2 \cdot 8$ & $21 \cdot 0 \pm 1 \cdot 7$ & $33 \cdot 7 \pm 1 \cdot 7$ \\
\hline & $110 \mathrm{mM}$ & $75 \mu \mathrm{M}$ & $56 \cdot 0 \pm 3 \cdot 0$ & $14 \cdot 5 \pm 1 \cdot 5$ & $29 \cdot 4 \pm 2 \cdot 4$ & $52 \cdot 6 \pm 1.8$ & $14 \cdot 1 \pm 0 \cdot 8$ & $33 \cdot 3 \pm 2 \cdot 4$ \\
\hline & 0 & $110 \mathrm{mM}$ & $53 \cdot 2 \pm 2 \cdot 2$ & $19 \cdot 2 \pm 1 \cdot 4$ & $27 \cdot 4 \pm 1 \cdot 3$ & NA & NA & NA \\
\hline
\end{tabular}

Table 5. Incorporation of methyl-14 $\mathrm{C}]$ methionine into the methylated lipids of $C$. neoformans by pulse labelling

c.p.m. were counted by liquid scintillation. Results show c.p.m. incorporation into methylated phospholipids for a typical experiment. NA, Not available.

\begin{tabular}{|c|c|c|c|c|}
\hline \multirow[t]{2}{*}{$\begin{array}{l}\text { Yeast } \\
\text { strain }\end{array}$} & \multirow[t]{2}{*}{$\begin{array}{l}\text { Glucose } \\
\text { concn }\end{array}$} & \multirow[t]{2}{*}{$\begin{array}{l}\text { Inositol } \\
\text { conch }\end{array}$} & \multicolumn{2}{|c|}{$\begin{array}{l}\text { Total c.p.m. } \\
\text { incorporation }\end{array}$} \\
\hline & & & $\begin{array}{l}\text { Without } \\
\text { choline }\end{array}$ & $\begin{array}{c}\text { With } \\
\text { choline } \\
(10 \mathrm{mM})\end{array}$ \\
\hline \multirow[t]{2}{*}{ A 6} & $110 \mathrm{mM}$ & 0 & $20632 \cdot 4$ & $14215 \cdot 0$ \\
\hline & $110 \mathrm{mM}$ & $75 \mu \mathrm{M}$ & $14164 \cdot 8$ & $816 \cdot 0$ \\
\hline \multirow[t]{3}{*}{$\mathrm{C} 20 \mathrm{a}$} & $110 \mathrm{mM}$ & 0 & $1071 \cdot 1$ & $309 \cdot 4$ \\
\hline & $110 \mathrm{mM}$ & $75 \mu \mathrm{M}$ & $2086 \cdot 8$ & $641 \cdot 8$ \\
\hline & 0 & $110 \mathrm{mM}$ & $594 \cdot 8$ & NA \\
\hline \multirow[t]{3}{*}{$\mathrm{C} 21 \alpha$} & $110 \mathrm{mM}$ & 0 & $4681 \cdot 1$ & $696 \cdot 2$ \\
\hline & $110 \mathrm{mM}$ & $75 \mu \mathrm{M}$ & $3728 \cdot 2$ & $566 \cdot 8$ \\
\hline & 0 & $110 \mathrm{mM}$ & $491 \cdot 6$ & NA \\
\hline
\end{tabular}

supplementation of the growth medium (Table 6). Growth of $C$. neoformans in SD-inositol medium (no glucose), however, led to a decrease in the amount of label incorporated into the inositol-containing sphingolipids.

\section{Inositol excretion assay}

To determine if the phospholipid composition was regulated independently of exogenous inositol due to excretion of internal inositol, strains $\mathrm{C} 20 \mathrm{a}$ and $\mathrm{C} 21 \alpha$ were

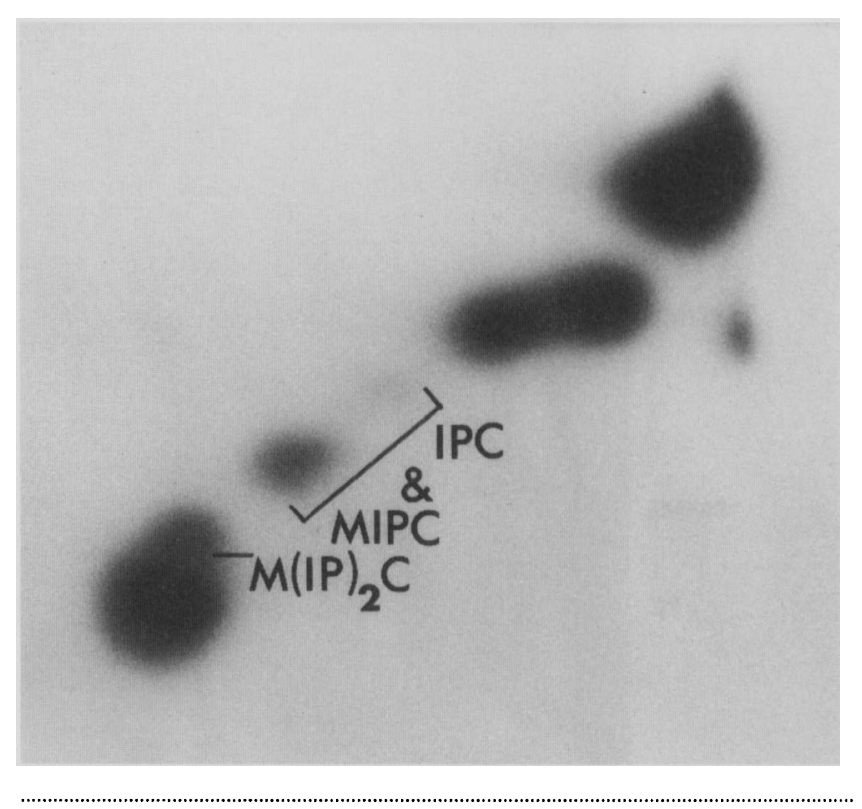

Fig. 4. Inositol-phosphate-containing sphingolipid composition. Autoradiogram of a two-dimensional chromatographic separation of ${ }^{32} \mathrm{P}$ steady-state labelled sphingolipids from strain C21 $\alpha$ grown in SD-inositol medium.

tested for inositol excretion. An $S$. cerevisiae strain AID (ade-1/ade-1, ino-1/ino-1, lys-2/+, bis-3/+, +/ade-5, a/ $\alpha$ ) was used as an indicator for the excretion of inositol by C. neoformans. In the presence of inositol this diploid $S$. cerevisiae strain produces red colonies. C. neoformans cells grown in SD-inositol medium were transferred to SD-glucose medium lacking inositol with the indicator strain AID. Growth of red S. cerevisiae colonies was not observed after 2 weeks of incubation with $C$. neoformans. This demonstrates that $C$. neoformans does not excrete inositol which may have accumulated intracellularly. 
Table 6. Analysis of inositol-containing sphingolipids in C. neoformans by steady-state labelling

c.p.m. were counted by liquid scintillation. Results show c.p.m. incorporation into sphingolipids for a typical experiment.

\begin{tabular}{|c|c|c|c|c|}
\hline \multirow[t]{2}{*}{$\begin{array}{l}\text { Yeast } \\
\text { strain }\end{array}$} & \multirow[t]{2}{*}{$\begin{array}{l}\text { Glucose } \\
\text { concn }\end{array}$} & \multirow[t]{2}{*}{$\begin{array}{l}\text { Inositol } \\
\text { concn }\end{array}$} & \multicolumn{2}{|c|}{$\begin{array}{l}\text { Total c.p.m. } \\
\text { incorporation }\end{array}$} \\
\hline & & & $\mathbf{M}(\mathbf{I P})_{2} \mathrm{C}$ & $\begin{array}{c}\text { MIPC + } \\
\text { IPC }\end{array}$ \\
\hline \multirow[t]{2}{*}{ A6 } & $110 \mathrm{mM}$ & 0 & 731.9 & $1852 \cdot 9$ \\
\hline & $110 \mathrm{mM}$ & $75 \mu \mathrm{M}$ & $288 \cdot 6$ & $773 \cdot 7$ \\
\hline \multirow[t]{3}{*}{$\mathrm{C} 20 \mathrm{a}$} & $110 \mathrm{mM}$ & 0 & $2574 \cdot 5$ & $7251 \cdot 5$ \\
\hline & $110 \mathrm{mM}$ & $75 \mu \mathrm{M}$ & $1245 \cdot 3$ & $2403 \cdot 3$ \\
\hline & 0 & $110 \mathrm{mM}$ & $1108 \cdot 2$ & $2175 \cdot 3$ \\
\hline \multirow[t]{3}{*}{$\mathrm{C} 21 \alpha$} & $110 \mathrm{mM}$ & 0 & $1629 \cdot 3$ & $6354 \cdot 5$ \\
\hline & $110 \mathrm{mM}$ & $75 \mu \mathrm{M}$ & $1414 \cdot 0$ & $5489 \cdot 8$ \\
\hline & 0 & $110 \mathrm{mM}$ & $993 \cdot 1$ & $2151 \cdot 8$ \\
\hline
\end{tabular}

\section{DISCUSSION}

Inositol is a key cellular metabolite which can be used by C. neoformans for the synthesis of membrane lipids and as an energy source for growth. This study examined the effects of exogenous inositol and choline on cell growth, lipid synthesis and lipid composition in two wild-type strains of $C$. neoformans, $\mathrm{C} 20 \mathrm{a}$ and $\mathrm{C} 21 \alpha$. Both a and $\alpha$ mating type strains grew at similar rates in SD medium with or without inositol and/or choline supplementation (Table 1). However, the growth rate decreases approximately twofold in SD-inositol medium (without glucose). The growth rate is further decreased by the presence of choline in this medium. $C$. neoformans was demonstrated to synthesize typically eukaryotic phospholipids by pulse labelling experiments with ${ }^{32} \mathrm{P}$, $\left[\right.$ metbyl $\left.{ }^{14} \mathrm{C}\right]$ methionine and $\left[{ }^{14} \mathrm{C}\right]$ choline (Tables 2 and 4$)$. These experiments also showed that PC synthesis occurs via both the de novo and auxiliary pathways (Fig. 1). Most importantly, the PI percentage of total phospholipid synthesized is relatively unaffected by the concentration of exogenous inositol in the growth medium. Steadystate labelling experiments revealed that the major phospholipids in the membranes of $C$. neoformans are PI, PS, PE and PC (Table 3). C. neoformans was shown to have the inositol-containing sphingolipids IPC, MIPC and $\mathrm{M}(\mathrm{IP})_{2} \mathrm{C}$ which are unique to yeast. The phospholipid composition data are in agreement with previous studies of $C$. neoformans lipids which were performed using complex growth medium (Itoh et al., 1975; Itoh \& Kaneko, 1977). Another report on the lipid composition of $C$. neoformans was unable to identify PS or sphingolipids (Rawat et al., 1984). This discrepancy may be due to differences in the extraction and/or separation techniques used for each study. The phospholipid composition analyses presented here indicate that exogenous inositol does not affect the proportion of inositol-containing phospholipids in the membranes of $C$. neoformans.

This study establishes that $C$. neoformans synthesizes inositol de novo. Specifically, pulse labelling experiments confirm that PI was synthesized in the membranes of cells grown for many generations in medium without inositol. Even though inositol prototrophy is typical of most eukaryotic cells, some fungi are natural inositol auxotrophs (Fernandez et al., 1986). Interestingly, C. neoformans is one of a few yeasts that use inositol as a carbon source (Barnett, 1976). Thus, this organism can serve as a model to study the coordination of inositol synthesis, uptake and catabolism.

C. neoformans, unlike most other yeasts, has the ability to grow on SD-inositol medium without glucose (Barnett, 1976). When choline is added to this medium, however, the cells' growth rate decreases. In contrast, choline does not affect the growth rate of $C$. neoformans in SD media with glucose as an energy source. Choline may be interfering with inositol uptake, inositol catabolism or lipid synthesis.

The addition of inositol and choline to the growth medium of $S$. cerevisiae alters the proportion of methylated lipids synthesized and decreases total N-MTF activity (Tables 3 and 4). The addition of choline with or without inositol to the growth medium of $C$. albicans alters the proportions of the methylated lipids and decreases $N$ MTF activity (Klig et al., 1990). Micromolar amounts of exogenous inositol in the growth medium of $C$. neoformans do not alter the relative proportion of the methylated phospholipids synthesized (Table 4) or the total amount of N-MTF activity (Table 5). The apparent decrease in total c.p.m. incorporation into methylated lipids when the cells are grown in SD-inositol medium is probably due to the decreased growth rate. Addition of choline only slightly alters the proportions of methylated lipids synthesized (Table 4); however, total N-MTF activity is decreased (Table 5). Thus, N-MTF activity in C. neoformans appears to respond to choline and is unaffected by inositol.

PI synthesis by $C$. neoformans strain $\mathrm{C} 20 \mathrm{a}$ is not altered by exogenous inositol in the medium (Table 2). Strain C21 $\alpha$ demonstrated a slight increase in PI synthesis when inositol was provided as the sole carbon source (in millimolar amounts). Supplementation of the growth medium of strain C21 $\alpha$ with micromolar amounts of inositol, however, does not result in a significant change in PI synthesis. In contrast, there is a dramatic increase in PI synthesis in $S$. cerevisiae when the growth medium is supplemented with even micromolar amounts of inositol. Steady-state lipid labelling experiments demonstrated that the overall phospholipid composition of both strains of C. neoformans is not affected by inositol, even when it is provided as the carbon source (Table 3). In contrast, the PI percentage of total membrane lipids in S. cerevisiae and C. albicans varies with inositol supplementation of the media (Culbertson et al., 1976; Klig et al., 1990). These data suggest that $C$. neoformans may possess a novel regulatory mechanism for stabilizing its membrane composition.

Three models offer possible mechanisms of a steady $C$. neoformans phospholipid composition despite variable 
environments. The first model proposes that de novo inositol synthesis results in an internal inositol concentration sufficient to fully saturate PI synthase. Addition of inositol to the growth media would have no effect on the already saturated PI synthase. The second model also involves de novo inositol synthesis, proposing that the internal inositol concentration is consistently sufficient to repress the N-MTFs. CDP-DAG is the common precursor for the synthesis of PI and the methylated phospholipids. Maintenance of repressed N-MTFs would result in a steady amount of CDP-DAG available for PI synthesis. Addition of inositol to the growth media would, again, have no effect on the already repressed $N$ MTFs resulting in a steady phospholipid composition. The third model proposes that $C$. neoformans maintains a constant internal inositol concentration. This pool size is not necessarily at saturating or repressing levels. This study suggests that the intracellular inositol concentration does not appear to be regulated by excretion. However, the internal inositol pool size could be controlled by regulating either inositol uptake or catabolism. A constant internal pool of inositol, regardless of inositol availability, would result in a steady phospholipid composition.

C. neoformans is surrounded by a polysaccharide capsule which has been shown to decrease the phagocytosis of $C$. neoformans by leukocytes (Kozel \& Cazin, 1971; Kozel \& Mastroianni, 1976; Kozel, 1977). The capsule is composed of a mannose backbone with xylose and glucuronic acid side chains (Bhattacharjee et al., 1979). In plants, inositol is a precursor of glucuronic acid and xylose (Moore \& Edman, 1993). It is interesting to speculate that in $C$. neoformans inositol catabolic products may be used for capsule synthesis.

Cryptococcal infections in immunocompromised individuals preferentially localized to the CNS where the concentration of inositol is high (Spector, 1976; Spector \& Lorenzo, 1975). Two unusual traits of $C$. neoformans are the utilization of inositol as a carbon source and maintenance of a constant PI percentage in its membranes. These traits may influence its localization to the inositolrich environment of the CNS.

\section{ACKNOWLEDGEMENTS}

The authors are indebted to Patton Garay, Carlos Najib, Dan Nice and Susan Ramos for their comments on the manuscript; to Marshet Girma for her assistance with the growth curves; and to Jim Archie for his assistance with the statistical analyses. These studies were supported by grants from the National Institutes of Health (DK45074-01) and the W. M. Keck foundation.

\section{REFERENCES}

Atkinson, K. D. (1984). Saccharomyces cerevisiae recessive suppressor that circumvents phosphatidylserine deficiency. Genetics 108, 533-543.

Bailis, A. M., Poole, M. A., Carman, G. M. \& Henry, S. A. (1987). The membrane-associated enzyme phosphatidylserine synthase is regulated at the level of mRNA abundance. Mol Cell Biol 7, $167-176$
Barnett, J. (1976). The utilization of sugars by yeasts. Adv Carbobydr Chem Biochem 32, 125-234.

Berridge, M. J. \& Irvine, R. F. (1984). Inositol trisphosphate, a novel second messenger in cellular signal transduction. Nature 312, 315-320.

Bhattacharjee, A. K., Kwon-Chung, K. J. \& Glaudemans, C. P. J. (1979). The structure of the capsular polysaccharide from Cryptococcus neoformans serotype D. Carbobydr Res 73, 183-192.

Buede, R., Rinker-Schaffer, C., Pinto, W. J., Lester, R. L. \& Dickson, R. (1991). Cloning and characterization of $L C B 1$, a Saccharomyces gene required for biosynthesis of the long-chain base component of sphingolipids. J Bacteriol 173, 4325-4332.

Bulmer, G. S., Sans, M. D. \& Gunn, C. M. (1967). Cryptococcus neoformans. I. Nonencapsulated mutants. J Bacteriol 94, 1475-1479.

Carman, G. M. \& Henry, S. A. (1989). Phospholipid biosynthesis in yeast. Annu Rev Biochem 58, 635-669.

Clark, R. A., Greer, D., Atkinson, W., Valainis, G. T. \& Hyslop, N. (1990). Spectrum of Cryptococcus neoformans infections in 68 patients infected with human immunodeficiency virus. Rev Infect Dis 12, 768-777.

Cross, G. A. M. (1990). Glycolipid anchoring of plasma membrane proteins. Annu Rev Cell Biol 6, 1-39.

Culbertson, M. R., Donahue, T. F. \& Henry, S. A. (1976). Control of inositol biosynthesis in Saccharomyces cerevisiae: properties of a repressible enzyme system in extracts of wild-type $\left(I N O^{+}\right)$cells. $J$ Bacteriol 126, 232-242.

Dickson, R. C., Wells, J. B., Schmidt, A. \& Lester, R. L. (1990). Isolation of mutant Saccharomyces cerevisiae strains that survive without sphingolipids. Mol Cell Biol 10, 2176-2181.

Dykstra, M. A., Friedman, L. \& Murphy, J. W. (1977). Capsule size of Cryptococcus neoformans: control and relationship to virulence. Infect Immun 15, 129-135.

Fernandez, S., Homann, M. J., Henry, S. A. \& Carman, G. M. (1986). Metabolism of the phospholipid precursor inositol and its relationship to growth and viability in the natural auxotroph Schizosaccharomyces pombe. J Bacteriol 166, 779-786.

Fromtling, R. A., Shadomy, H. J. \& Jacobson, E. S. (1982). Decreased virulence in stable, acapsular mutants of Cryptococcus neoformans. Mycopatbologia 79, 23-29.

Greenberg, M. L., Goldwasser, P. \& Henry, S. A. (1982). Regulatory mutants of inositol biosynthesis in yeast: isolation of inositol excreting mutants. Genetics 100, 19-33.

Hill, J. E., Chung, C., McGraw, P., Summers, E. \& Henry, S. A. (1990). Biosynthesis and the role of phospholipids in yeast membranes. In Biochemistry of Cell Walls and Membranes in Fungi, pp. 245-260. Edited by P. J. Kuhn, A. P. J. Trinci, M. L. Jung, M. W. Goosen \& L. G. Coping. Berlin: Springer-Verlag.

Hokin, M. E. \& Hokin, L. E. (1953). Enzyme secretion and the incorporation of $\mathrm{P}^{32}$ into phospholipids of pancreas slices. J Biol Chem 203, 967-977.

Itoh, T. \& Kaneko, H. (1977). The in vivo incorporation of ${ }^{32} \mathrm{P}-$ labelled orthophosphate into pyrophosphatidic acid and other phospholipids of Cryptococcus neoformans through cell growth. Lipids 12, 810-813.

Itoh, T., Waki, H. \& Kaneko, H. (1975). Changes of lipid composition with growth phase of Cryptococcus neoformans. Agric Biol Cbem 39, 2365-2371.

Jacobson, E.S. \& Emery, H. S. (1991). Catecholamine uptake, melanization, and oxygen toxicity in Cryptococcus neoformans. $J$ Bacteriol 173, 401-403.

Jacobson, E. S., Ayers, D. J., Harrell, A. C. \& Nicholas, C. C. (1982). 
Genetic and phenotypic characterization of capsule mutants of Cryptococcus neoformans. J Bacteriol 150, 1292-1296.

Kelley, M. J., Bailis, A. M., Henry, S. A. \& Carmen, G. (1988). Regulation of phospholipid biosynthesis in Saccbaromyces cerevisiae by inositol: inositol is an inhibitor of phosphatidylserine synthase activity. J Biol Chem 263, 18078-18085.

Kennedy, E. P. \& Weiss, S. B. (1956). The function of cytidine coenzyme in the biosynthesis of phospholipids. J Biol Chem 222, 193-214.

Klig, L. S., Homann, M. J., Carman, G. M. \& Henry, S. A. (1985). Coordinate regulation of phospholipid biosynthesis in Saccbaromyces cerevisiae: pleiotropically constitutive opi1 mutant. J Bacteriol 162, 1135-1141.

Klig, L. S., Homann, M. J., Kohlwein, S. D., Kelley, M. J., Henry, S. A. \& Carman, G. M. (1988). Saccharomyces cerevisiae mutant with a partial defect in synthesis of CDP-diacylglycerol and altered regulation of phospholipid biosynthesis. J Bacteriol 170, 1878-1886.

Klig, L. S., Friedli, L. \& Schmid, E. (1990). Phospholipid biosynthesis in Candida albicans: regulation by the precursor inositol and choline. J Bacteriol 172, 4407-4414.

Konemane, W. \& Roberts, G. D. (1985). Preliminary identification of fungal cultures. In Practical Laboratory Mycology, p. 152. Baltimore, MD: Williams and Williams.

Kozel, T. R. (1977). Non-encapsulated variant of Cryptococcus neoformans. II. Surface receptors for cryptococcal polysaccharide and their role in inhibition of phagocytosis by polysaccharide. Infect Immun 16, 99-106.

Kozel, T. R. \& Cazin, J., Jr (1971). Nonencapsulated variant of Cryptococcus neoformans. I. Virulence studies and characterization of soluble polysaccharide. Infect Immun 3, 286-294.

Kozel, T. R. \& Mastroianni, R. P. (1976). Inhibition of phagocytosis by cryptococcal polysaccharide: dissociation of the attachment and ingestion phases of phagocytosis. Infect Immun 14, 62-67.

Kwon-Chung, K. J. \& Bennett, J. E. (1978). Distribution of $\alpha$ and a mating types of Cryptococus neoformans among natural and clinical isolates. Am J Epidemiol 108, 337-340.

Kwon-Chung, K. J. \& Bennett, J. E. (1992). Cryptococcosis. In Medical Mycology, pp. 397-446. Edited by C. Cann. Philadelphia: Lea and Febiger.

Kwon-Chung, K. J. \& Edman, J. C. (1992). Recent advances in the molecular genetics of Cryptococcus neoformans. In Frontiers of Infectious Disease: New Strategies in Fungal Disease, pp. 195-207. Edited by J. E. Bennett, R. Hay \& P. K. Peterson. New York: Churchill Livingston.

Kwon-Chung, K. J. \& Rhodes, J. C. (1986). Encapsulation and melanin formation as indicators of virulence in Cryptococcus neoformans. Infect Immun 51, 218-223.

Kwon-Chung, K. J., Polacheck, I. \& Popkins, T. (1982). Melaninlacking mutants of Cryptococcus neoformans and their virulence in mice. J Bacteriol 150, 1414-1421.

Kwon-Chung, K. J., Edman, J. C. \& Wickes, B. L. (1992). Genetic association of mating types and virulence in Cryptococcus neoformans. Infect Immun 60, 602-605.

Moore, T. D. E. \& Edman, J. C. (1993). The $\alpha$-mating type locus of Cryptococcus neoformans contains a peptide pheromone gene. Mol Cell Biol 13, 1962-1970.

Musial, C. E., Cockerill, F. R., III \& Roberts, G. D. (1988). Fungal infections of the immunocompromised host: clinical and laboratory aspects. Clin Microbiol Rev 1, 349-364.

Odds, F. C. (1987). Candida infections : an overview. CRC Crit Rev Microbiol 15, 1-5.

Olivera, A., Buckley, N. E. \& Spiegel, S. (1992). Sphingomyelinase and cell-permeable ceramide analogs stimulate cellular proliferation in quiescent Swiss 3T3 fibroblasts. $J$ Biochem Mol Biol 267, 26126-26127.

Paulus, H. \& Kennedy, E. P. (1960). The enzymatic synthesis of inositol monophosphatide. J Biol Chem 235, 1303-1311.

Pinto, W. J., Srinivasan, B., Shepherd, S., Schmidt, A., Dickson, R. C. \& Lester, R. L. (1992). Sphingolipid long-chain-base auxotrophs of Saccharomyces cerevisiae: genetics, physiology, and a method for their selection. J Bacteriol 174, 2565-2574.

Polacheck, I., Hearing, V. I. \& Kwon-Chung, K. J. (1982). Biochemical studies of phenoloxidase and utilization of catecholamine in Cryptococcus neoformans. J Bacteriol 150, 1212-1220.

Polacheck, I., Platt, Y. \& Aronovitch, J. (1990). Catecholamine and virulence of Cryptococcus neoformans. Infect Immun 58, 2919-2922.

Poole, M. A., Homann, M. J., Bae-Lee, M. S. \& Carman, G. M. (1986). Regulation of phosphatidylserine synthase from Saccharomyces cerevisiae by phospholipid precursors. J Bacteriol 168, 668-672.

Randhawa, R. E. \& Paliwal, D. K. (1979). Survey of Cryptococcus neoformans in the respiratory tract of patients with bronchopulmonary disorders and in the air. Sabouraudia 17, 399-404.

Rawat, D. S., Upreti, H. B. \& Das, S. K. (1984). Lipid composition of Cryptococcus neoformans. Microbiologica 7, 299-307.

Rhodes, J. C., Polacheck, I. \& Kwon-Chung, K. J. (1982). Phenoloxidase activity and virulence in isogenic strains of Cryptococcus neoformans. Infect Immun 36, 1175-1184.

Smith, S. W. \& Lester, R. L. (1974). Inositol phosphorylceramide, a novel substance and the chief member of a major group of yeast sphingolipids containing a single inositol phosphate. $J$ Biol Chem 249, 3395-3405.

Spector, R. (1976). Inositol accumulation by brain slices in vitro. $J$ Neurocbem 27, 1273-1276.

Spector, R. \& Lorenzo, A. V. (1975). myo-Inositol transport in the central nervous system. Am J Pbysiol 228, 1510-1518.

Steiner, S. \& Lester, R. L. (1972). Studies on the diversity of inositol-containing yeast phospholipids: incorporation of 2-deoxyglucose into lipid. $J$ Bacteriol 109, 81-88.

Steiner, S., Smith, S., Waechter, C. J. \& Lester, R. L. (1969). Isolation and partial characterization of a major inositol-containing lipid in baker's yeast, mannosyl-diinositol, diphosphoryl-ceramide. Proc Natl Acad Sci US A 64, 1042-1048.

Waechter, C. J. \& Lester, R. L. (1973). Differential regulation of the $\mathrm{N}$-methyltransferases responsible for phosphatidylcholine synthesis in Saccharomyces cerevisiae. Arch Biocbem Biophys 158, 401-410.

Wang, Y. \& Casadevall, A. (1994). Susceptibility of melanized and nonmelanized Cryptococcus neoformans to nitrogen- and oxygenderived oxidants. Infect Immun 62, 3004-3007.

Yamashita, S., Oshima, A., Nikawa, J. I. \& Hosaka, K. (1982). Regulation of the phosphatidylethanolamine methylation pathway in Saccbaromyces cerevisiae. Eur J Biochem 128, 589-595.

Received 17 January 1995; revised 21 March 1995; accepted 6 April 1995. 